\title{
DISEASE PHOBIA IN PATIENTS WITH TEMPOROMANDIBULAR JOINT PAIN ASSESSED BY THE ILLNESS ATTITUDE SCALE
}

\author{
Christos Stavrianos ${ }^{1}$, Panagiotis Kafas ${ }^{2}$, Waseem Jerjes ${ }^{3}$, Tahwinder Upile ${ }^{4}$, Irene Stavrianou ${ }^{5}$, Ioannis Nazaroglou ${ }^{5}$, \\ Georgios Kafas $^{6}$
}

Aristotle University, Thessalonica, School of Dentistry, Greece: Department of Endodontics ${ }^{1}$, Department of Oral Surgery ${ }^{2}$; UCLH Head and Neck Centre, London, United Kingdom ${ }^{3}$; Royal National Throat Nose and Ear Hospital, London, United Kingdom ${ }^{4}$; Private Practice, Thessalonica, Greeces; Core Trainee, Camden and Islington NHS Trust, London, United Kingdom ${ }^{6}$

Summary: Disease phobia refers to a psychological state when the person continuously thinks that he/she is sick and improvement from the condition is impossible. Disease phobia in patients suffering from pain, secondary to temporomandibular disorders (TMDs), is usually the consequence of long-term problems; diagnosis and treatment of this group is a real challenge for healthcare professionals. Aim: The purpose of this prospective study was to objectively evaluate the role of Illness Attitude Scale (Kellner or IAS) in measuring cancerophobia and heart disease phobia in patients suffering from pain, as a consequence of TMDs. Subjects and Methods: The cohort included 22 patients with TMDs who underwent evaluation of these phobias; pain was acute in 7 and chronic in 15 . The patients were asked to complete the "Kellner" questionnaire, and this was followed by full clinical examination of the temporomandibular region. Results: When measuring the correlation between the cancerophobia and heart disease phobia patients, the outcome was found significant in the total cohort, $\mathrm{p}<0.01$. Comparisons were carried out in the chronic group $(\mathrm{n}=15)$ and was significant $(\mathrm{p}=0.034$ and $\mathrm{r}=0.549)$; while in the acute group no significance was identified. Conclusion: Cancerophobia and heart disease phobia in TMD patients are factors that need to be taken in consideration when managing chronic pain in this group.

Key words: TMJ pain; Phobia; Attitudes

\section{Introduction}

Pain is defined as an unpleasant sensory and/or emotional experience associated with actual or potential tissue damage (9). Pain may be classified into short-term (acute) and long-term (chronic) (11). The differentiation between acute and chronic pain can be difficult and guidelines varies among centres. An acute episode is characterised by a "sharp" onset due to local inflammatory effect followed by tissue damage and usually resolves within few hours to twelve weeks (2); while chronic pain is known to be "dull" and last longer than 3 months. This may also apply to pain in the temporomandibular region. Management of pain here depends on the duration of symptoms, nature (arthrogenic or myogenic) and any other associated symptoms ( 8 , 10); which can include clicking, locking, trismus, jaw deviation, swelling, ear fullness, tinnitus and headache $(3,6)$.

Psychological factors have been implicated in pain in TMD patients, but the mechanism is not fully understood yet. Phobias have been reported in this group of patients which can be described as an irrational fear or hatred, which is significant enough to be manifested as an illness (1). Such special group (phobic patients) should be managed with care; early psychiatric involvement and continuous reassurance should be implemented (8).

Specific questionnaires are used when such underlying problems are identified $(8,12,15)$. The Illness Attitude Scale (IAS) is used in assessing attitudes in hypochondriacs and patients with abnormal illness behaviour (17). Cancerophobia and heart disease phobia are two common psychological entities which can be assessed by the Illness Attitude Scale.

The aim of this prospective study was to apply the IAS to assess the relationship between phobia (cancerophobia and heart disease phobia) and pain (acute or chronic) in patients with termporomandibular disorders.

\section{Subjects and Methods}

The protocol of the study was approved by the Local Ethics Committee for Human Research. The work was in accordance with the Declaration of Helsinki and its amend- 
ments. Patients were provided with information sheets explaining the purpose of the study in non-scientific terms and provided informed consent.

The cohort included 22 consecutive temporomandibular disorders patients. There were 14 females with a mean age of 33.2 years and 8 males with a mean age of 37.8 years. Inclusion criteria were patients between 16-55 years of age with acute or chronic pain secondary to TMD. Patients with bone pathology, trauma and ongoing degenerative joint process were excluded from the study. Three months duration was the cut off between acute and chronic pain.

Recruited patients fell under the first two groups (myopathy and arthropathy) of Axis-I of the "Research Diagnostic Criteria for TMDs" (RDC-TMD), (16). The patients were asked to complete the "Kellner" or "IAS" questionnaire, and this was followed by full clinical examination to the temporomandibular region.

The Illness Attitude Scales were developed by Robert Kellner as a clinimetric index for measuring hypochondriacal fears and beliefs. The scales have been extensively used in the past two decades. According to the guidelines of Kellner, the items are distributed in the following way within the 9 IAS: 1 . Worry about illness (items 1-3); 2. Concerns about pain (items 4-6); 3. Health habits (items 7-9); 4. Hypochondriacal beliefs (items 10-12); 5. Thanatophobia (items 13-15); 6. Disease phobia (items 16-18); 7. Bodily preoccupations (items 19-21); 8. Treatment experience (items 22-24); 9. Effects of symptoms (items 25-27).

The facial part of the examination involved inspection, palpation and auscultation. The muscles of mastication palpated included the masseter, temporalis and medial and lateral pterygoids; assessment for tenderness, stiffness and muscle bulk took place. The joint noises (clicking, crepitations) were assessed by palpation of the preauricular region during jaw movement and auscultation. Full examination of all the 12 cranial nerves took place as part of the facial assessment.

The intra-oral part of the examination involved inspection of the dento-oral tissues, occlusion and assessment of the cranial nerves that supplies the oral cavity.

\section{Statistical analysis}

Descriptive statistics were applied to assess the correlation between (acute and chronic) pain patients and cancerophobia and heart disease phobia using SPSS 13 statistical package. Chi-square and Pearson tests were applied to assess for significance.

\section{Results}

Performing X2, the patients reporting cancerophobia linearly suffered from heart disease phobia $(\mathrm{p}<0.01)$; (using Pearson: $\mathrm{p}=0.001$ and Pearson's $\mathrm{r}=0.650$ ).

The reliability analysis showed that Illness Attitude Scale was reliable with Cronbachs Alpha $=0.7865$ and F-ra- tio $=0.0504$. Furthermore, performing a stepwise linear regression, the heart disease phobia acted as a predictor for cancerophobia $(\mathrm{p}=0.001)$.

The $95 \%$ confidence interval for the difference was used to measure the interval estimation with an associated probability (0.05) - which was found to be 1.10-2.07 for cancerophobia and 1.11-2.15 for heart disease phobia where the mean is 1.64 and 1.68 , respectively.

Histograms were created to show distribution of the cancerophobic and heart disease phobic patients on the Illness Attitude Scale (Figures 1 and 2). While in figure 3, the distribution of both groups of phobic patients is expressed in relation to the Illness Attitude Scale.

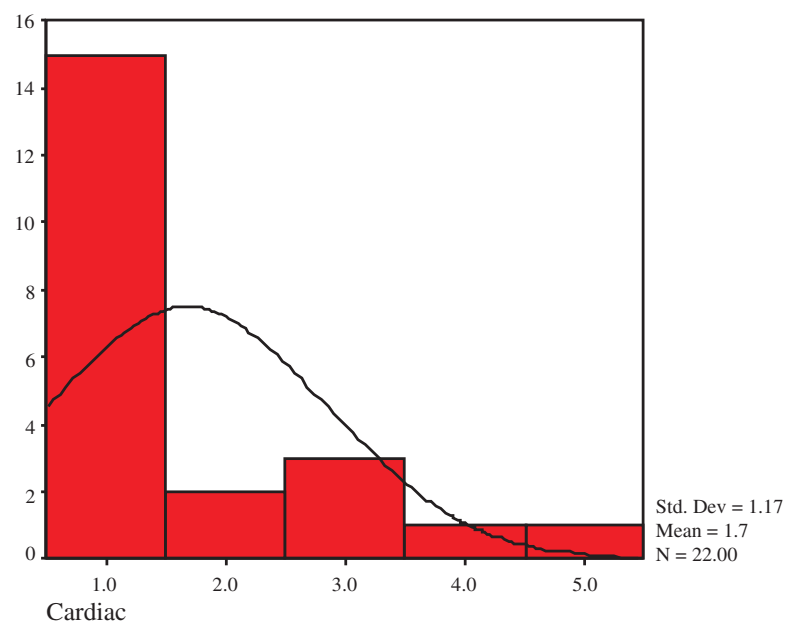

Fig. 1: Histogram showing the distribution of the heart disease phobic patients on the Illness Attitude Scale. The Yaxis represents the number of patients with heart disease phobia, while the X-axis indicates the severity of the scale.

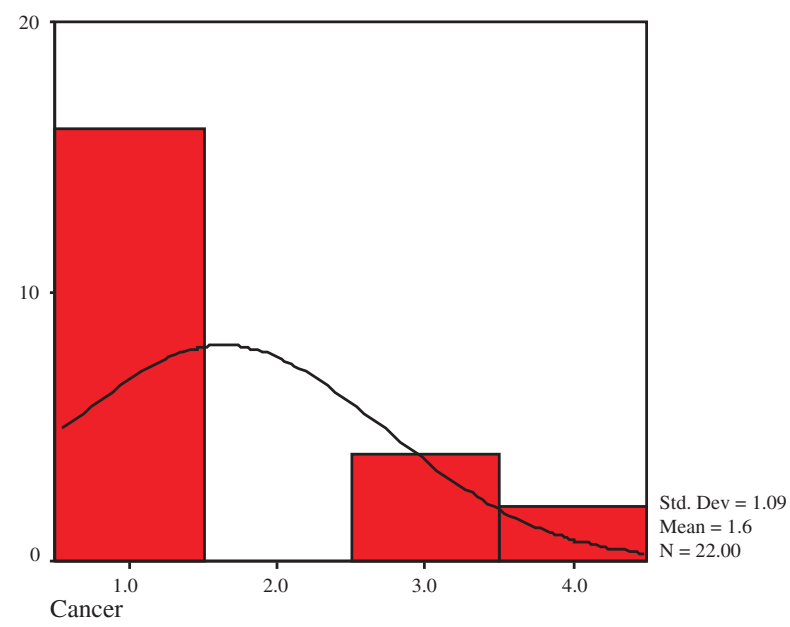

Fig. 2: Histogram showing the distribution of the cancerophobic patients on the Illness Attitude Scale. The Y-axis represents the number of patients with cancerophobia, while the $\mathrm{X}$-axis indicates the severity of the scale. 


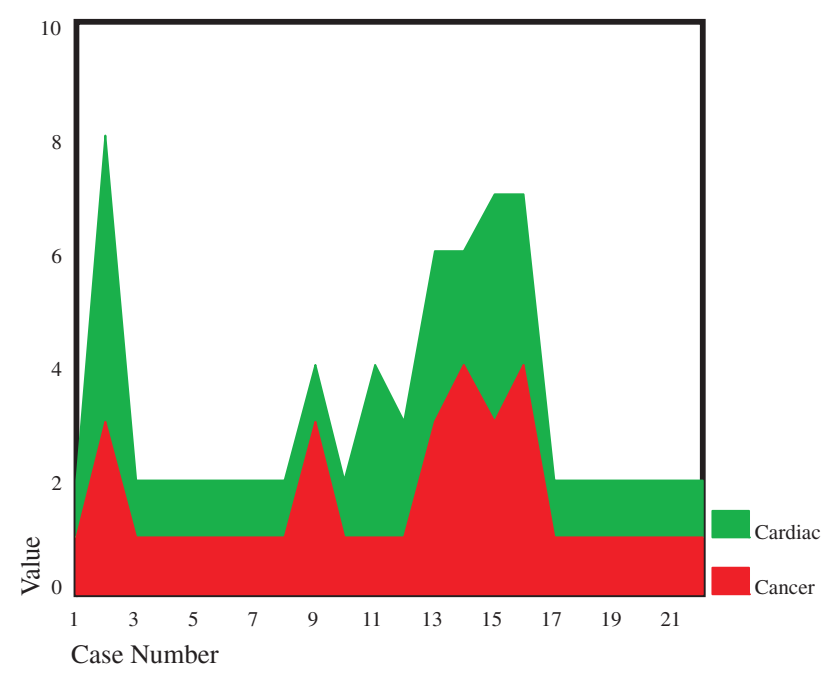

Fig. 3: The distribution of heart disease phobic and cancerophobic patients in relation to the "severity" of the Illness Attitude Scale.

Comparisons were carried out in the chronic group $(\mathrm{n}=15)$ and was significant $(\mathrm{p}=0.034$ and $\mathrm{r}=0.549)$; while in the acute group no significance was identified.

\section{Discussion}

Disease phobia refers to a psychological state when the person continuously thinks that he/she is sick and improvement from the condition is impossible. Disease phobia in patients suffering from pain, secondary to temporomandibular disorders (TMDs), is usually the consequence of long-term problems; diagnosis and treatment of this group is a real challenge for healthcare professionals.

The Illness Attitudes Scale (IAS) is a self-rated measure that consists of nine subscales designed to assess fears, attitudes and beliefs associated with hypochondriacal concerns and abnormal illness behaviour $(7,17)$. The VI subgroup can be used to measure the disease phobia in chronic pain in TMD patients.

The importance of "Illness Attitude Scale" lies in the chronic pain group. Pain presentation in chronic terms suggests that this could be linked or associated with conversion reaction (15). Psychosocial stressors are temporarily related to the conversion of unconscious psychological conflict into a loss of normal function (13).
Correct approach to pain in TMD patients should involve clinical and psychosocial evaluation. History taking is the most important diagnostic method, with informed reassurance being the most reliable management. This approach was found very useful in around $80 \%$ of patients when used in conjunction with simple analgesics, physiotherapy and occlusal splints (12). Informed reassurance and placebo were found to be effective in relieving symptoms in $45 \%$ of patients (5). Early intervention may prevent the development of chronicity $(4,14)$.

Chronic pain in TMD patients is known to be associated or result in stress, anxiety and depression; cancerophobia and heart disease phobia in TMD patients are factors that need to be taken in consideration when managing chronic pain in TMD patients.

\section{References}

1. Collins Cobuild English Language Dictionary. $4^{\text {th }}$ ed. Suffolk: Williams Collins Sons \& Co Ltd, 1990:1075

2. Cousins M. Acute and postoperative pain. In: Wall PD, Melzack R, eds. Textbook of Pain. Edinburgh: Churchill Livingstone, 1994:357-85.

3. Drangsholt M, LeResche L. Temporomandibular disorder pain. In: Crombie IK, ed. Epidemiology of Pain. Seattle WA: IASP Press, 1999:203-33.

4. Epker J, Gatchel RJ, Ellis E. A model for predicting chronic TMD: practical application in clinical settings. J Am Dent Assoc 1999;130:1470-5

5. Feinmann C, Harris M. Psychogenic facial pain. Part 2: Management and prognosis. Br Dent J 1984;156:205-8.

6. Feinmann C, Harrison S. Liaison psychiatry and psychology in dentistry J Psychosom Res 1997;43:467-76

7. Hadjistavropoulos HD, Frombach IK, Asmundson GJ. Exploratory and confirmatory factor analytic investigations of the Illness Attitudes Scale in a nonclinical sample. Behav Res Ther 1999;37:671-84.

8. Harris M, Feinmann C, Wise M, Treasure F. Temporomandibular joint and orofacial pain: clinical and medicolegal management problems. Br Dent J 1993; 174:129-36.

9. International Association for the Study of Pain (IASP). Pain terms: a list with definitions and notes on usage. Recommended by the IASP Subcommittee on Taxonomy. Pain 1979;6:249.

10. Kafas P, Chiotaki N, Stavrianos C, Stavrianou I. Temporomandibular joint pain: diagnostic characteristics of chronicity. J Med Sci 2007;7:1088-92.

11. Kafas P, Leeson R. Assessment of pain in temporomandibular disorders: the biopsychosocial complexity. Int J Oral Maxillofac Surg 2006;35:145-9.

12. Mitchell L, Mitchell DA. Oral medicine. In: Mitchell L, Mitchell DA, eds. Oxford Handbook of Clinical Dentistry. New York: Oxford University Press, 1999: 438-89.

13. Neligh GL. Somatoform and Associated Disorders. In: Scully JH, ed. NMS Psychiatry. Philadelphia: Williams and Wilkins, 1996:167-93.

14. Newton-John T, Madland G, Feinmann C. Chronic idiopathic orofacial pain: II What can the general dental practitioner do? Br Dent J 2001;191:72-3.

15. Ogus HD, Toller PA. The common disorders. In: Ogus HD, Toller PA, eds Common Disorders of the Temporomandibular Joint. Bristol: John Wright \& Sons, 1986:20-31

16. Steenks MH, de Wijer A. Validity of the research diagnostic criteria for temporomandibular disorders Axis I in clinical and research settings. J Orofac Pain 2009;23:9-16.

17. Stewart SH, Watt MC. Illness Attitudes Scale dimensions and their associations with anxiety-related constructs in a non clinical sample. Behav Res Ther 2000; 38:83-99.

Submitted December 2008. Accepted June 2009.

\section{Corresponding author:}

Panagiotis Kafas, 3 Kassandrou, 65404 Kavala, Greece; e-mail: pankafas@yahoo.com 